\title{
Cômparison of Accuracy of Self-Developing Films and Conventional Films for Radiographic Determination of Distance between File Tip and Radiographic Apex in Root Canal Therapy
}

\author{
Parichehr Pourshakibaei ${ }^{1}$, Mohammad Taghi Mashkouri Najafi ${ }^{2}$, Amir Hossein Akbari Zahmati*2, \\ Mehrnoush Afiat ${ }^{2}$, Masoumeh Vaghari ${ }^{2}$
}

1. Dental Research Center, Golestan University of Medical Sciences, Gorgan, Iran

2. Student Research Committee, School of Dentistry, Golestan University of Medical Sciences, Gorgan, Iran

\begin{abstract}
Background and objectives: The developing process is necessary for converting a latent image into a visible image in conventional dental x-ray films. Despite the considerable advances made in development of radiographic equipment, there are also still some unresolved issues in this field. New self-developing film is an alternative to manual processing. The purpose of this study was to compare accuracy of self-developing films and conventional films (E-speed) for determination of the distance between file tip and radiographic apex in root canal therapy in laboratory conditions.

Methods: This study was done on 25 single-canal, single-rooted premolar teeth. After obtaining tooth length, each tooth was accessed and K-files No. 15 and 25 were placed inside the canal tip to tip with the tooth apex. Then, $1 \mathrm{~mm}$ of the actual tooth length was reduced and periapical radiographs were captured using self-developing films and conventional films (E-speed) under standard conditions. Two endodontists observed the films twice at different intervals. The obtained data were analyzed with SPSS software (version 18) using paired t-test.

Results: Average distance between the tip of file No.15 to the radiographic apex in conventional film and self-developing film was $0.37 \mathrm{~mm}$ and $0.35 \mathrm{~mm}$, respectively. The mean working length measured using K-file No. 25 was $0.44 \mathrm{~mm}$ in conventional film and $0.40 \mathrm{~mm}$ in self-developing film. There was no statistically significant difference between the two methods for measuring the working length.

Conclusion: The self-developing films provide a radiographic image that is diagnostically equivalent to the conventional film for measurement of the distance from the file tip to the radiographic apex in single-rooted teeth with a single canal.
\end{abstract}

KEYWORDS: Self-developing film, radiographic apex, conventional film

Received: 2018/11/27 $\quad$ Revised: 2018/12/24 $\quad$ Published:2019/01/12

*Correspondence: Amir Hossein Akbari Zahmati

Address: Faculty of Dentistry, Golestan University of Medical Sciences, Gorgan, Iran

Telephone: +98-9357188386 Email: a.akbari@goums.ac.ir 


\section{INTRODUCTION}

Today, the use of radiography in dentistry has spread widely and its value in the diagnosis, prognosis and treatment of oral and dental diseases, especially in root canal therapy is irrefutable. Determining the correct working length is essential for successful cleaning and filling of the root canal system. It should be noted that radiography is the method of choice for measuring the working length (1). In 1899, Kelz used radiography for the first time for determining root length. Later, Faxon and colleagues used this system in 1955 to investigate root canal obturation (2). Latent images produced by conventional $\mathrm{x}$-ray systems become visible through darkroom processing with chemicals that can cause environmental pollution and allergies. To solve this problem, modern systems such as digital imaging have been developed, but the high cost of installation and running such systems can be a disadvantage $(1,3)$. A new generation of self-developing $\mathrm{X}$-ray films was introduced to the market to resolve the problems associated with conventional filmbased radiography. Compared to conventional techniques, the newer technique is faster and makes early and appropriate diagnosis possible. However, longer exposure time and decreased quality of obtained images over time are amongst its disadvantages $(4,5)$. At the beginning of root canal therapy, it is essential to accurately measure the distance from the file tip to the radiographic apex. In this study, we compare accuracy of selfdeveloping and conventional E-speed intraoral radiographic films for determining the working length by measuring the distance between the file tip and the radiographic apex in single-rooted teeth with a single canal.

\section{MATERIAL AND METHODS}

This study was conducted on 25 single-rooted and single-canal premolar teeth in order to compare the accuracy of conventional Espeed and self-developing Ergonom $\mathrm{X}$ intraoral films for determining the working length (distance from the file tip to the radiographic apex).

First, a pilot study was carried out to optimize preparation and exposure conditions for both types of films. Then, 25 freshly extracted premolar teeth were selected among 50 collected teeth according to the following criteria: being single rooted with a single canal and no crack, corrosion and calcification. The teeth were placed in $5.25 \%$ sodium hypochlorite solution for 24 hours for disinfection and removal of debris from the outer surface of the root. Then, they were stored in a mixture of $70 \%$ alcohol and glycerol to prevent drying (5).

An access cavity was created for each tooth using Turbine Frezfisher No. 743 (Tizkavan Co., Iran). The $\mathrm{K}$ file size 15 and 25 are commonly used in root canal therapy; size 15 is used for determining the working length of canal and size 25 is for recapitulation and determining master apical length. A K-file No. 15 (Manny Co., Japan) was placed within the canal via the access cavity. As soon as the tip of the file was visible by magnifier from the end of the apex, the file's rubber stop was set on the coronal reference point. Next, the file was removed and the distance from the rubber stop to the file tip was measured accurately with a graded caliper. This length represents the actual tooth length and is $1 \mathrm{~mm}$ longer than the working length.

The teeth were numbered and four x-ray radiographs were prepared for each tooth while placed inside a human mandible to simulate natural conditions. The mandible was then fixed in Styrofoam (expanded polystyrene foam) at a specified distance from the films. Then, file No. 15 was placed inside the canal, $1 \mathrm{~mm}$ shorter than the tooth length (working length).

An E-speed conventional intraoral film (Kodak, USA) was placed parallel to the tooth and in a certain place inside the Styrofoam. Periapical radiograph was prepared through parallel method and using an extraoral x-ray unit (Planmeca, Finland), operating at kvp 70, $8 \mathrm{~mA}$ and $0.12 \mathrm{~s}$ exposure time. Without 
changing the position of the mandible, the Espeed film was removed and then prepared according to the manufacturer's instructions and using the same radiographic device operating at $\mathrm{kvp} 70,8 \mathrm{~mA}$ and $0.32 \mathrm{~s}$ exposure time. The conventional periapical E-speed films were developed and fixed in an automatic film processor (Hope, USA) in 6 minutes at $30{ }^{\circ} \mathrm{C}$.

Self-developing films were developed manually according to the manufacturer's instructions. Briefly, the film was held vertically in a way that the bag containing the developing solution was positioned above. Then, by pouring the bag containing the solution downward, the fluid was pushed toward the bag. The solution was rubbed thoroughly on the film for 50 seconds. After developing, the films were turned upside down and the liquid was returned to the original bag. The film was removed and washed with water for 10 minutes. The remaining liquid was removed by rubbing fingers on the film. Later, file No. 15 was removed and file No.25, one mm shorter than the tooth length, was placed within the canal. Periapical radiographs under the mentioned conditions using the E-Speed conventional films and self-developing films.

Four radiographs were made for each tooth using conventional E-Speed film (one with file 15 and one with file 25) and selfdeveloping film (one with file 15 and one with file 25). Overall, 100 radiographs were obtained for 25 teeth. Afterwards, the radiographies along with an attached checklist were randomly given to two observers (endodontists) in two stages at different time intervals to determine the working length. In order to avoid bias, a second series of observation was done four weeks later. This study was conducted in a double blind manner, as the specialists were not aware of the film types. The observers examined the films based on their skills and experience. The endodontists examined the images on negatoscope and recorded the distance between the file tip and the radiographic apex using Endometer (A017800000000, Dentsply, USA) on the checklist. Mean values of the recorded working lengths was calculated. Finally, data were analyzed with SPSS software (version 18) using paired t-test.

\section{RESULTS}

There was no statistically significant difference between the mean values of working length reported by the observers (Table 1).

Table 1. Comparison of mean value of working length measured by the observers

\begin{tabular}{|c|c|c|}
\hline Observer & Mean \pm SD $(\mathbf{m m})$ & P-value * \\
\cline { 1 - 2 } 1 & $23.16 \pm 2.17$ & \multirow{2}{*}{0.8} \\
\hline 2 & $23.15 \pm 2.19$ & \\
\hline
\end{tabular}

* T-test

We also found no difference in the mean values of working length between the two films when using file No. $15(\mathrm{P}=0.061)$

(Table 2).

Table 2. Comparison of the mean values of working length measured using files No. 15 and 25 in Ergonom-X self-developing film and conventional E-speed (Kodak) film

\begin{tabular}{|c|c|c|c|c|c|c|}
\hline Type of film & K-file & Mean \pm SD $(\mathbf{m m})$ & P-value & K-file & Mean \pm SD $(\mathbf{m m})$ & P-value* \\
\hline Self-developing & No. 25 & $0.35 \pm 0.32$ & \multirow{2}{*}{$0.61 *$} & No. 15 & $0.40 \pm 0.31$ & \multirow[b]{2}{*}{0.19} \\
\hline Conventional & No. 25 & $0.36 \pm 0.30$ & & No. 15 & $0.44 \pm 0.33$ & \\
\hline
\end{tabular}

* T-test 
Similarly, the mean values of working length did not differ significantly between the two films when using file No. $25(\mathrm{P}=0.19)$. Using different file sizes did not significantly alter the mean lengths measured in the two methods (Table 3).

Table 3. Comparison of the mean values of working length measured using files No. 15 and 25 in Ergonom-X self-developing film and conventional E-speed (Kodak) film

\begin{tabular}{|c|c|c|c|c|}
\hline Type of film & K-file & Number & Mean \pm SD (mm) & P-value* \\
\hline Self-developing & No. 15 & 25 & $0.32 \pm 0.35$ & 0.22 \\
\cline { 2 - 4 } & No. 25 & 25 & $0.40 \pm 0.31$ & \\
\hline Conventional & No. 15 & 25 & $0.36 \pm 0.30$ & \multirow{2}{*}{0.05} \\
\cline { 2 - 4 } & No. 25 & 25 & $0.44 \pm 0.33$ & \\
\hline
\end{tabular}

* T-test

Table 3 shows the average distance between the tip of the files and the radiographic apex in the two methods. There was no significant difference between the calculated lengths.

\section{DISCUSSION}

Accurate measurement of the working length is crucial for a successful root canal therapy (6). Several factors including radiation angle, exposure time, film receptor and clinical position of the tooth affect this measurement (7). In this study, we compared accuracy of working length determination between selfdeveloping films and conventional films, and found no significant difference between the two methods in terms of image quality and resolution. The use of file size 15 and 25 also had no significant impact on the mean lengths obtained by the two methods. These findings indicate that there is no significant difference between the accuracy of Ergonom-X selfdeveloping films and E-speed conventional films for determination of the working length. However, conventional films yielded a slightly better image quality.

Similar to our findings, in 2000, Eikenberg and Vandre also found no difference between the images of Ergonom-X self-developing films with developing time of 50 seconds and D-speed (Kodak) films manually processed in 80 seconds (10). They also found that changing the file size from 10 to 15 decreases error value from $0.92 \mathrm{~mm}$ to $0.77 \mathrm{~mm}$ in
The mean length $(0.44 \pm 0.33 \mathrm{~mm})$ obtained from the E-speed films with file No. 25 was closes to the optimal working length $(1 \mathrm{~mm}$ short of the radiographic apex of the teeth.

conventional films. However, we observed no change in the measurement error when using different file sizes in self-developing films ( $0.83 \mathrm{~mm}$ for both file sizes).

In our study, changing the file size from 15 to 25 increased the mean value of working length from $0.35 \mathrm{~mm}$ to $40 \mathrm{~mm}$ in selfdeveloping films but decreased the mean value from $0.36 \mathrm{~mm}$ to $0.44 \mathrm{~mm}$ in conventional films. Thus, one can infer that using a larger file would increase the accuracy of working length determination in conventional E-speed films.

Alshwaimi et al. measured mesiobuccal root of 30 first maxillary molar teeth and stated that E-speed films yield a better quality and higher resolution image compared to selfdeveloping and D-speed films, which is inconsistent with our findings. The contradiction in the results may be due to differences in the methods used and parameters evaluated in each study.

Eikenberg reported that self-developing films are the method of choice in military fields or emergency conditions considering the lack of 
facilities (4). The use of self-developing films is also recommended for implant surgery, surgeries that require immediate diagnosis as well as procedures on elderly, mentally retarded and handicapped patients. However, they have numerous shortcomings compared to conventional $\mathrm{x}$-ray films including lomger exposure time, the lack of protective lead foil in the envelope for reducing radiation and high costs (9). We conducted the study with a double-blind approach to eliminate the errors encountered in previous studies $(10,11)$.

\section{CONCLUSION}

Our results show that there is no significant difference between the accuracy of selfdeveloping films and conventional E-speed films for determining the root canal working length for single-rooted premolar teeth with a single canal.

\section{ACKNOWLEDGMENTS}

We would like to thank the deputy of Research and Technology of Golestan University of Medical Sciences for supporting this study.

\section{DECLARATIONS}

\section{Funding}

This study was financially supported by the Golestan University of Medical Sciences, Iran.

\section{Ethics approvals and consent to participate Not applicable.}

\section{Conflict of interest}

There is no conflict of interest to declare regarding the publication of this article.

\section{REFERENCES}

1. White SC, Pharoah MJ. Oral radiology: principles and interpretation: Elsevier Health Sciences; 2014.

2. Foxon G, Griffith J, Price M. Cineradiographic Techniques. The British journal of radiology. 1955;28(330):336-8. [DOI:10.1259/0007-128528-330-336]
3. Torabinejad M, Fouad A, Walton RE. Endodontics-e-book: Principles and practice. Elsevier Health Sciences; 2014:242-63.

4. Eikenberg S, Dolley G. Detection of interproximal caries using methods applicable to a field environment: digital radiography, manually processed film, and self-developing film. Military medicine. 2001; 166(4):338-41. [DOI:10.1093/milmed/166.4.338]

5. Mentes A, Gencoglu N. Canal length evaluation of curved canals by direct digital or conventional radiography. Oral Surgery, Oral Medicine, Oral Pathology, Oral Radiology, and Endodontology. 2002;93(1):88-91. [DOI:10.1067/moe.2002.119466]

6. Viner MD, Robson J. Post-Mortem Forensic Dental Radiography-a review of current techniques and future developments. Journal of Forensic Radiology and Imaging. 2017 ;8:22-37. [DOI:10.1016/j.jofri.2017.03.007]

7. Farida A, Maryam E, Ali M, Ehsan M, Sajad Y, Soraya K. A comparison between conventional and digital radiography in root canal working length determination. Indian Journal of Dental Research. 2013 ;24(2):229-33.

[DOI:10.4103/0970-9290.116693]

8. AlShwaimi E, Majeed A. Perceived quality, clarity, and accuracy of manually processed and self-developing radiographs in endodontics. International journal of health sciences. 2013;7(2):116-23. [DOI:10.12816/0006034]

9. Robillard JJ, inventor; Scully Richard L 1425 Seminole Trail Suite 310 Charlottesville Birginia 22906, assignee. Photosensitive compositions for direct positive color photography. United States patent US 4,725,527. 1988 Feb 16.

10. Eikenberg LS, Vandre CR. Comparison of digital dental X-ray systems with self-developing film and manual processing for endodontic file length determination. Journal of endodontics. 2000;26(2):65-7. [DOI:10.1097/00004770200002000-00001]

11. Sobouti F, Hadian H, Abdi S, Babaei Hatkehlouei M, Salimi N, Dadgar S. Radiographic Comparison of Apical Root Resorption During Orthodontic Treatment with Bracket Slot Size 
Journal of Clinical and Basic Research (JCBR): 2019: Vol 3: N.1.P: 1-5

0,018-inch and 0,022-inch. Gazi Medical Journal.

2018;29(3):223-6. 